\title{
Influence of Boron Content on the Fracture Toughness and Fatigue Crack Propagation Kinetics of Bainitic Steels
}

K. F. Rodríguez-Galeano ${ }^{1}$, A. Mestra ${ }^{2}$, R. Rodríguez-Baracaldo ${ }^{1}$, J.J. Olaya-Florez ${ }^{1}$, J.M. Cabrera ${ }^{2}$

1. Departamento de Ingeniería Mecánica, Facultad de Ingeniería, Universidad Nacional de Colombia, Carrera 45 \# 26-85, Bogotá, Colombia.

2. Departamento de Ciencia de los Materiales e Ingeniería Metalúrgica, Universitat Politécnica de Catalunya, Av. Diagonal 647, 08028, Barcelona, Spain.

\begin{abstract}
The relatively good combination of high strength and ductility makes bainitic steels a candidate to replace many other steels in industrial applications. However, in service, ductility and strength are not up to standard requirements. In many industrial components, toughness and fatigue performance are also very relevant. In the present study, bainitic steels with varying content of boron were fabricated, with the aim of analyzing the fracture toughness and changes in the fatigue life. The results show that a relatively small change in the boron content can cause a notable variation in the fracture toughness of bainitic steels. The maximum value obtained in fracture tiughnes was for the steel with the highest boron content. It was observed that the amount of interlath martensite constituents decreases in steels with the addition of boron, leading to the promotion and presence of void coalescence and therefore a a remarkable rise in the toughness of bainitic steels. An increase on the fatigue life of the bainitic steels with an increase in the boron content was also observed, through analysis by means of Paris' law. A comprehensive micrographic study was carried out in order to examine the mechanics of fatigue crack growth in the bainitic steels, revealing small longitudinal cracks in bainitic steels that lack boron. These cracks tend to disappear in bainitic steels that contain boron. To elucidate this behavior, micrographs of the surfaces generated by the crack growth process were taken, showing that several nano-cracks appeared between the bainite laths. It is finally argued that this high-energy consumption process of nano-crack nucleation and growth is the reason for the improved toughness and fatigue life observed in bainitic steels.
\end{abstract}

Key Words: bainitic steel, toughness, crack growth, fatigue life.

\section{Introduction}

Bainitic steels are regarded as relatively new steels, because not long ago it was impossible to produce them in the industry with the required strength and toughness. Their use became more extensive when low-carbon bainitic steels were introduced by Irvine and Pickering in the 60 's [1-2]. After that, a great deal of research was carried out on bainitic steels, taking into consideration processing, chemical composition, and heat treatments in order to obtain good performance. Many of those studies have revealed that bainitic steels have better properties than other steels for specific tasks. Nowadays, steels with a bainitic microstructure are widely used in building construction, pipelines, automotive applications, and railway rails and crossings, since they have an optimum combination of mechanical properties for the production of final parts after cold-stamping or cold-forming [3-5].

However, there has been controversy in the literature that deals with bainitic steels, due to the not well-understood nature of the austenitic decomposition to bainite. This is partially because bainite is formed over a wide range of temperatures and with diverse morphologies [6]. At the same time, the effect of alloying elements such as boron, chrome, molybdenum, manganese, niobium, and other elements introduces an additional variable to the morphology and mechanical properties of bainite [7-9]. Although initially bainitic steels were considered to be brittle, nowadays it has been proven that they have a relatively high degree of toughness, which is the reason that scientists continue studying the dependence of toughness and crack propagation on the chemical composition, microstructure, and processing conditions of these type of steel [10-16]. 
As a fabrication parameter of the bainitic steels, the carbon content of the residual austenite must not exceed the concentration given by the so called $T_{o}^{\prime}$ curve concept [17]. Accordingly it follows that the maximum amount of bainite that can be obtained is limited, and other phases, such as cementite, carbon-enriched retained austenite, martensite, and so on, can appear in bainitic steels. It is well known that some of these phases mixed into bainitic steels are detrimental for toughness, leading to research for new ways of processing to suppress the precipitation of cementite and avoid the formation of other constituents such as austenite and proeutectoid ferrite [17].

Another important alloying element that should be considered when steels are designed for heat treatment is boron. The role of boron as a hardenability agent has been widely recognized, but there is a lack of agreement in the literature about the effect of boron content on the bainitic transformation and the toughness behavior. Yang et al. [18] pointed out that as the boron content increases, the impact toughness rapidly deteriorates, but Lan et al. [19] conclude that the addition of boron is beneficial for the promotion of bainitic transformation at lower temperatures. Wang et al. [20] show that there is a critical boron content, in relation to the carbon content, for achieving the complete bainitic transformation. They show that in ultra-low-carbon bainitic steels the effect on the toughness does not greatly deteriorate until the boron content is more than $40 \mathrm{ppm}$. Moreover, Tamehiro et al. [21] concluded that the optimum boron concentration is about $10 \mathrm{ppm}$, and Melloy et al. [22] proposed that an optimum value is reached with the addition of about $20 \mathrm{ppm}$ of boron in C-Mn-Mo base composition steel with a bainitic microstructure, because the deterioration of the boron hardenability factor and toughness is attributed to the formation of a boron constituent identified as $\mathrm{Fe}_{23}(\mathrm{CB})_{6}$.

Fatigue behavior is also an interesting topic with respect of bainitic steels when they are put into service. There are a few studies of the fatigue crack growth in bainitic rail steels. When they are compared with classical pearlitic rail steels, it has been concluded that bainitic steels exhibit superior wear resistance, excellent weldability [23, 24, 25], and better behavior under fatigue work conditions $[10,11,26]$. However, there exists a lack of studies in the literature concerning how boron content affects fatigue crack growth in bainitic steels. For this reason, in the present study the fatigue crack growth of bainitic steels is studied as a function of the boron content, establishing a relation between boron content and crack growth parameters.

\section{Materials and Experimental Procedure}

Bainitic steels were prepared using a $50 \mathrm{~kg}$ vacuum induction melting furnace. Table 1 shows the chemical composition of the base steel. Various amounts (parts per million - ppm) of boron were added to that composition (referred to as 20,40, and 60). Cast ingots with a square transversal area of $70 \times 70 \mathrm{~mm}^{2}$ were made. These ingots were then maintained at $1100^{\circ} \mathrm{C}$ for 2 hours, removed from the furnace, and immediately hot-pressed to a thickness of $22 \mathrm{~mm}$ in several steps before their temperature fell below $900^{\circ} \mathrm{C}$. Finally, they were allowed to cool in air. The steel blocks were classified according to the average content of boron as: $20 \mathrm{~B}$ (20 ppm), 40B (40 ppm), 60B (60 ppm) and OB (no boron content). 
Table 1. Chemical composition (wt\%) of the steel.

\begin{tabular}{ccccccc}
\hline $\mathrm{C}$ & $\mathrm{Si}$ & $\mathrm{Mn}$ & $\mathrm{Mo}$ & $\mathrm{Cr}$ & $\mathrm{V}$ & $\mathrm{Ti}$ \\
\hline 0.32 & 1.45 & 2.0 & 0.26 & 1.26 & 0.1 & 0.002 \\
\hline
\end{tabular}

Specimens, were machined parallel to the longitudinal rolling direction (see Figure 1 ), and polished using standard methods for metallographic examination until diamond paste of $1 \mu \mathrm{m}$, and then they were etched with $4 \%$ picral in order to reveal the bainitic microstructure. The microstructures were observed by scanning electron microscopy (SEM) using a JEOL JSM-5610 microscope. Optical microscopy was used to measure the bainitic packet size of the etched samples. Additionally, X-ray diffraction measurements were performed using Panalytical X'Pert PRO MPD equipment with CuK $\alpha$ radiation, with a wavelength of $1.54 \AA$ and an intensity ratio of 0.5 .

The toughness tests were performed at room temperature. The 3-point bending test procedure was performed according to standard ASTM E1820-11 [27], using an universal testing machine INSTRON 5862 with a constant crosshead speed of $0.025 \mathrm{~mm} / \mathrm{s}$. Single-edge notched bend specimens $\mathrm{SE}(\mathrm{B})$ were machined with dimensions of $7.5 \times 15 \times 67.5 \mathrm{~mm}$ (thickness $x$ height $x$ width). Samples where cut in the L-S orientation, as shown in Figure 1. A pre-crack length of $1.3 \mathrm{~mm}$ was formed for each specimen in order to have a target geometrical correction factor $(\mathrm{a} / \mathrm{W})$ of 0.5 , monitored via optical microscopy. Data from the toughness test were collected by machine (load- displacement) and with a Crack Opening Displacament COD extensometer specified in standard ASTM E1820-11 [27], with time intervals of $0.240 \mathrm{~s}$; ; both calculation methods were used, in order to verify the toughness values obtained.

Fatigue crack growth and fracture toughness were measured in identical single-edge notched bend $S E(B)$ specimens than those for fracture toughness tests.. To provoke crack propagation, a RUMUL resonance fatigue machine was used. The stress intensity factor $\mathrm{K}$ applied was changed by force variation. Measurements of the number of cycles and the crack propagation were taken for each specific variation of $\mathrm{K}$. The fatigue tests were conducted at room temperature, under load control conditions using a sinusoidal wave-form at a frequency of 10 $\mathrm{Hz}$. The ratio of minimum to maximum stress $\mathrm{R}$ was 0.1 . The crack propagation was measured with an OLYMPUS BX41M optical microscope and an image analyzer. Fracture surfaces were observed using the above-named SEM microscope. Longitudinal fractures were observed in the rolling direction. Transverse cracks were observed directly on the cracked surface generated in the crack growth tests. 


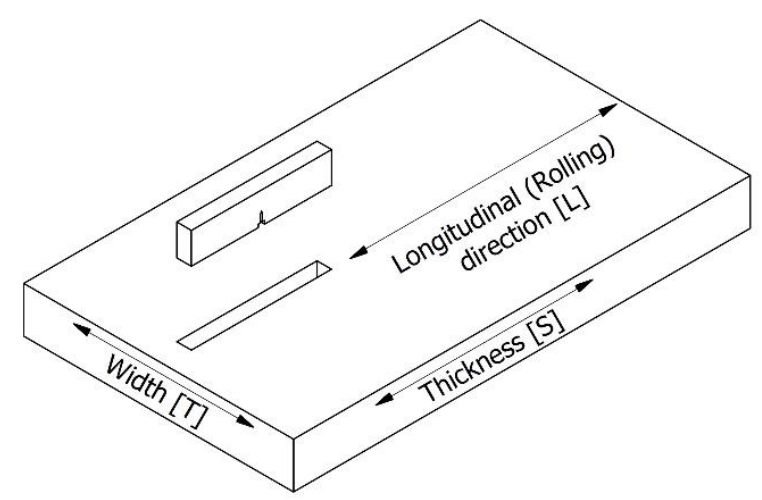

Figure 1. Orientation of the samples.

\section{Results}

\subsection{Microstructural analysis}

Figure 2 shows the microstructures obtained for steels a) OB, b) 20B, c) $40 \mathrm{~B}$, and d) $60 \mathrm{~B}$. It is readily apparent that bainite plates appear as the principal microconstituent in different grains. The strain axis is coaxial with the horizontal direction of the micrographs,. No great effect on the boron content can be seen in the microstructures. Analogously, magnification of samples $40 \mathrm{~B}$ and $60 \mathrm{~B}$ in Figure 3 reveals that there are small areas of martensite/austenite $(\mathrm{M} / \mathrm{A})$ constituents inside the bainite packets. Furthermore, Figure 4, obtained via transmission electron microscopy (TEM), confirms the presence of interlath retained austenite films in the microstructure of a sample with only a small addition of boron (20B). These films sometimes exhibit a typical wavy morphology, characteristic of the bainite in high-silicon steels [15].

The bainitic packet size was measured via optical microscopy. The packet size is given by $l=\sqrt{l_{1} l_{2}}$, where $l_{1}$ and $l_{2}$ are the average packet length and width, respectively. The average size for each steel was taken to be the mean value of more than forty carefully measured packets in each steel sample [29]. No relevant changes were noticed in the value of the bainitic packet size of the steel samples, obtaining a mean value of $32.39 \mu \mathrm{m}$.
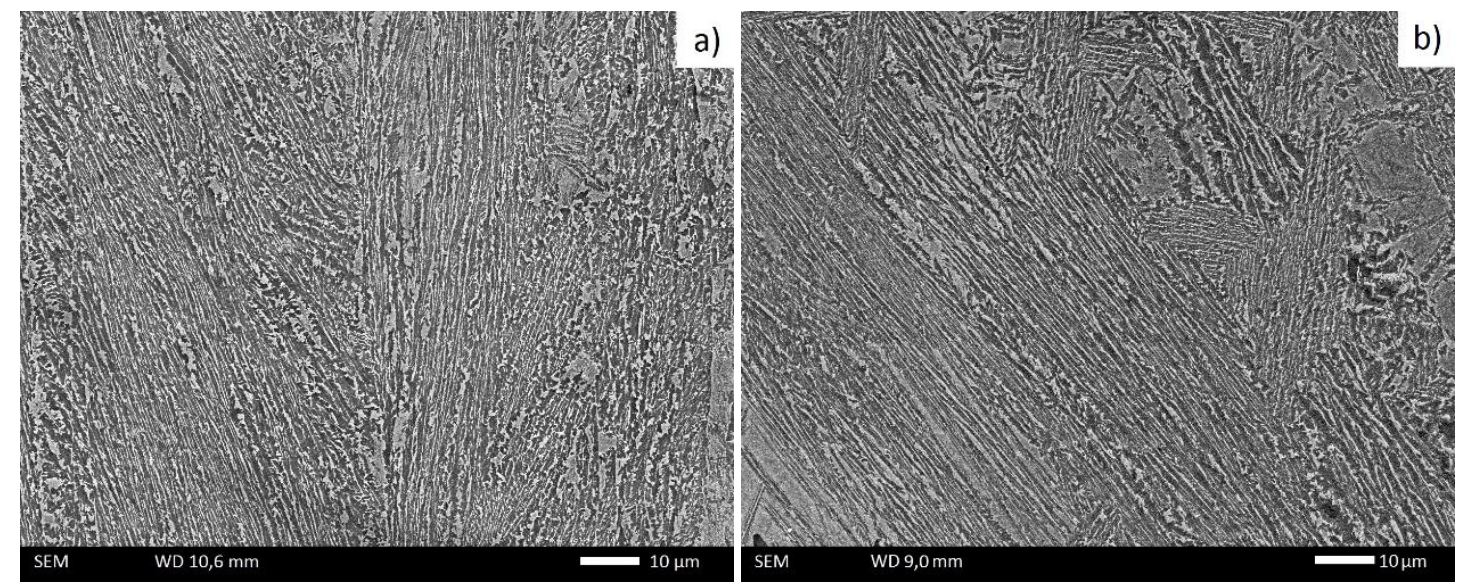

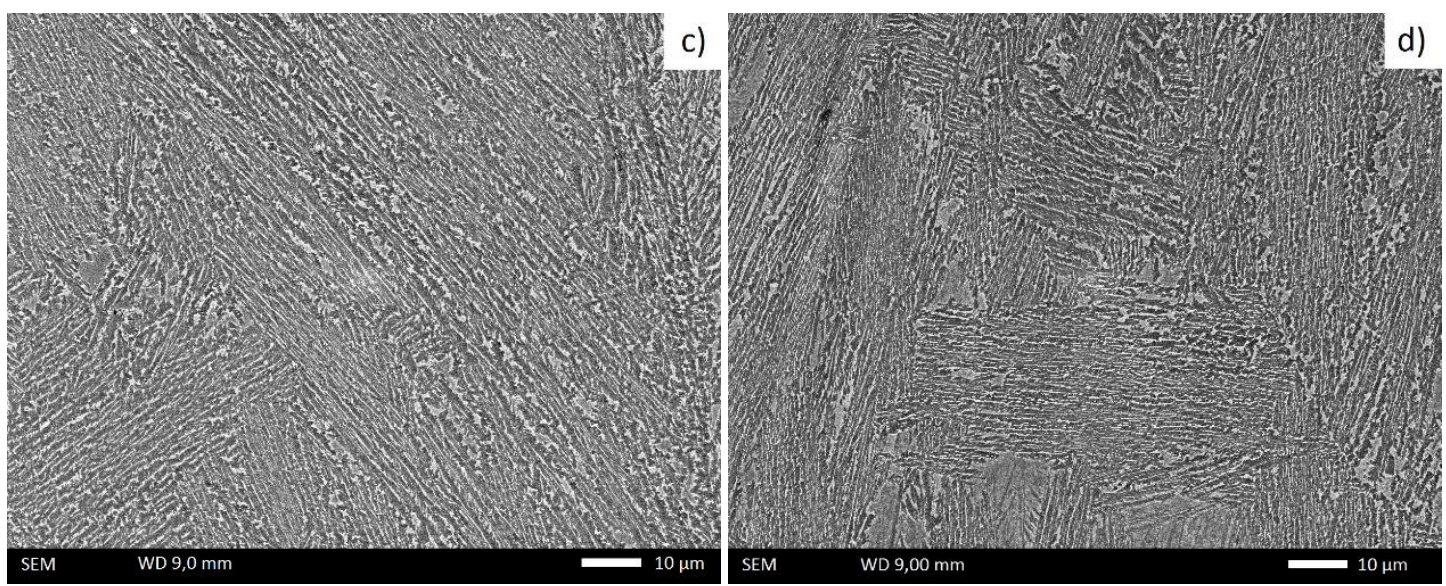

Figure 2. SEM micrograph of the bainitic microstructure in steel specimens a) 0B, b) 20B, c) 40B, and d) $60 \mathrm{~B}$.
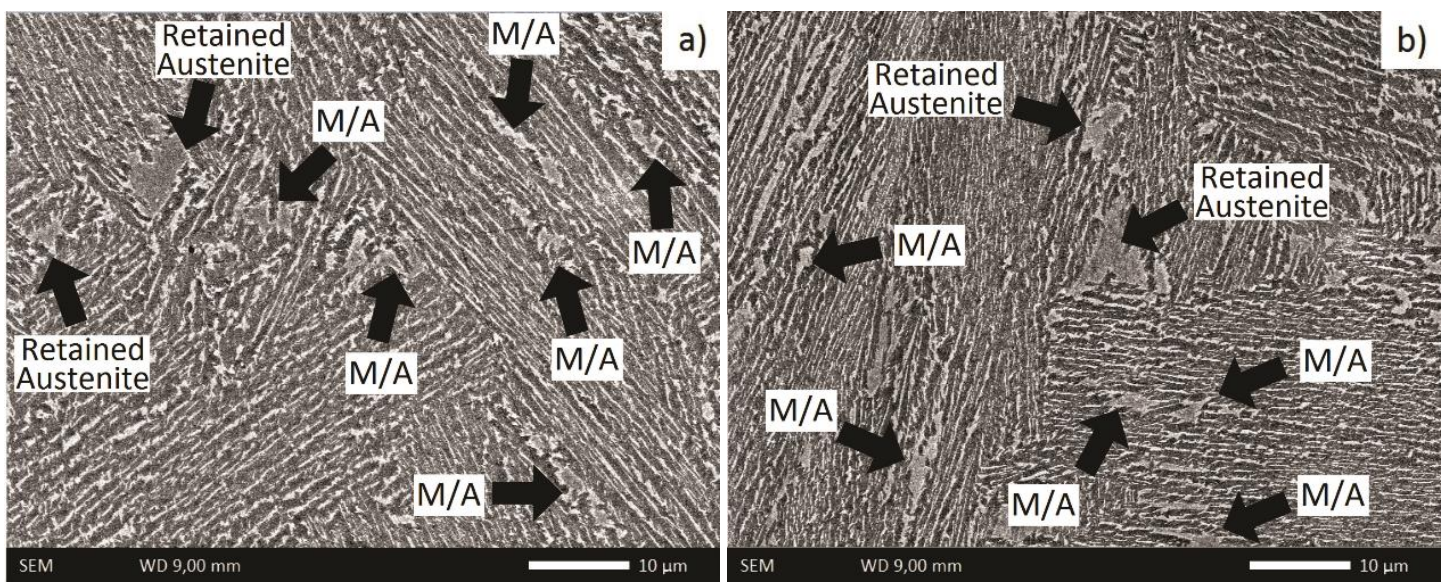

Figure 3. Micrograph of the bainitic steels a) 40B, b) 60B. There are small martensite/austenite constituent grains inside parallel bainitic plates.

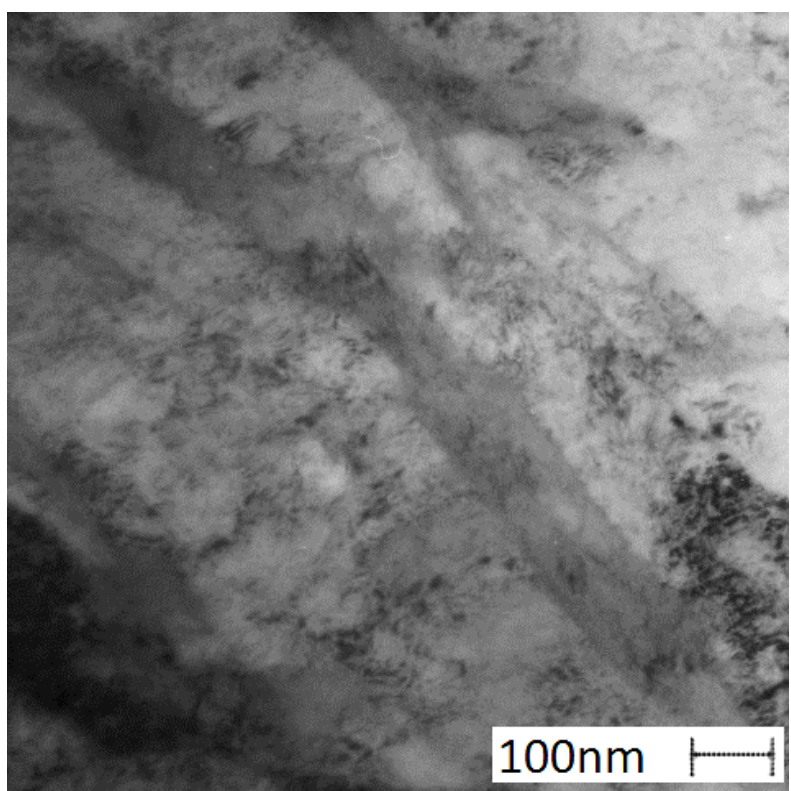

Figure 4. Transmission electron micrograph revealing bainitic ferrite with intervening films of retained austenite. 
Figure 5 shows the X-Ray diffraction (XRD) pattern of the steel samples. The presence of peaks of ferrite (Fe $\alpha$ ), austenite (Feץ), and martensite are evident. Austenite and martensite peaks decrease with higher boron content. Results obtained via XRD analysis software also reveal the presence of Titanium boride $B_{2} T i$ in bainitic steel 60B. Titanium boride is a common secondphase particle present in steels [30]. In low quantities, titanium boride provides ductility. Other authors [22] have pointed out the formation of a boron constituent identified as $\mathrm{Fe}_{23}(C B)_{6}$ when boron content exceeds $25 \mathrm{ppm}$. However, it is not easy to determine its presence using XRD unless the steel has a relatively high-volume fraction of that constituent, in which case it appears as particular peaks, close to steel-phases peaks.

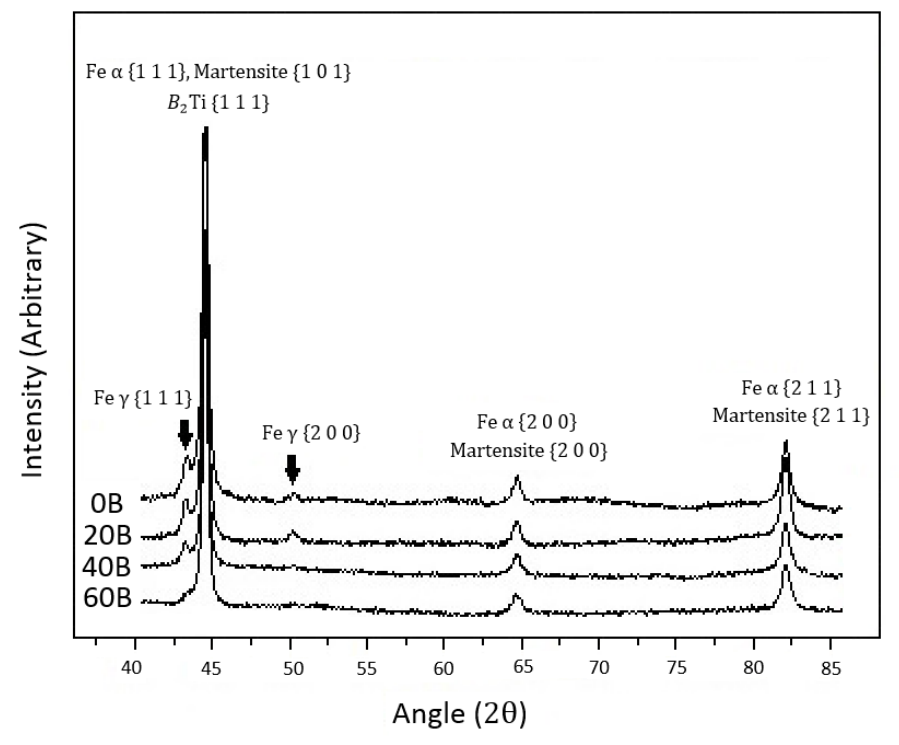

Figure 5. X-Ray Diffraction image of bainitic steels with various ppm of boron.

\subsection{Fracture toughness of bainitic steels with added boron}

Fracture toughness test results are plotted in Figure 6 for all the steels that were manufactured. It was found that the addition of boron leads to an improvement in the impact toughness of bainitic steels. In accordance with other authors [31], when the amount of added boron increases in bainitic steels, thin film-like retained austenite appears as a transformed product of large blocks of retained austenite transformation, which is mechanically more stable, and there tends to be enhanced toughness in bainitic steels with the addition of boron. Moreover the enhancement in toughness of bainitic steel $20 \mathrm{~B}$ is just over $8 \%$ in comparison with bainitic steel $\mathrm{OB}$. That improvement in toughness is not as notable as the increase obtained with respect to the other steels, which is about $15 \%$ and $16 \%$, comparing the results of steel samples $20 B$ with $40 B$ and $40 B$ with $60 B$, respectively.

Toughness in bainitic steels is directly related to the high volume fraction of bainite reached in the microstructure. XRD results shown in Figure 5 are consistent with the enhancement of toughness expected when the presence of unstable blocky austenite is avoided and the amount of martensite is reduced [15], especially for bainitic steel samples with higher boron content. 


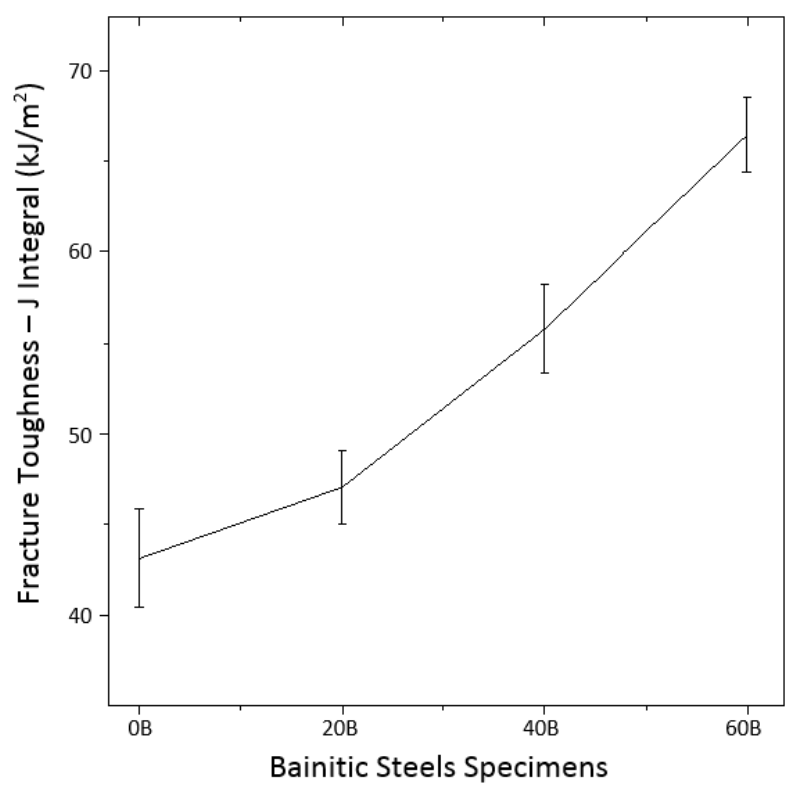

Figure 6. Curve of behavior of Integral $\mathrm{J}$ fracture toughness vs ppm of boron in the composition of bainitic steel.

\subsection{Fatigue Crack Propagation (FCP) Kinetics}

Figure 7 summarizes the behavior of the fatigue crack growth of the present bainitic steels in terms of the crack growth rate $(\mathrm{da} / \mathrm{dN})$ and the threshold stress intensity factor $\Delta K$. The results fit quite well to Paris' law (Equation 1)

$$
\frac{d a}{d N}=C(\Delta K)^{m}
$$

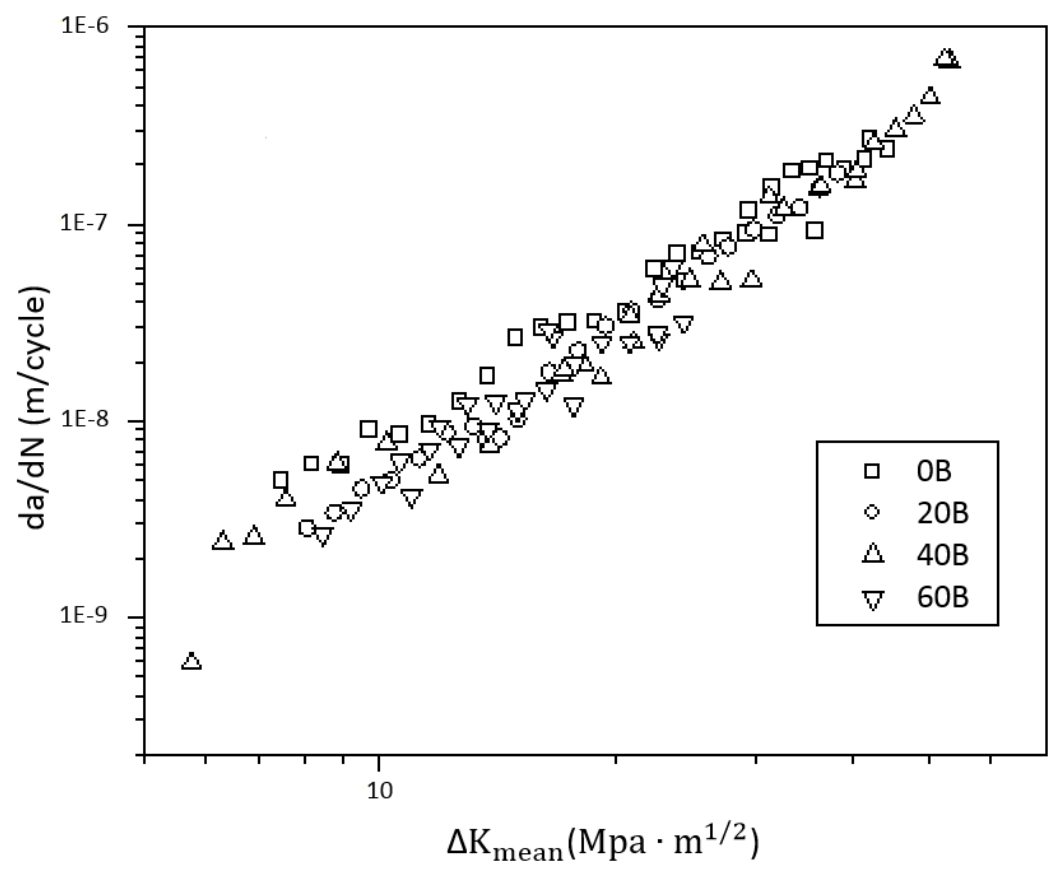


Figure 7. Crack growth rate, da/dN, versus stress mean intensity factor $\Delta K_{\text {mean }}$ in the present bainitic steels as a function of the samples with added boron.

Table 2. Paris law constants for the studied bainitic steels as a function of the samples with added boron.

\begin{tabular}{ccc}
\hline Bainitic Steels & & \\
& C & $m$ \\
\hline $0 \mathrm{~B}$ & $3.00 \mathrm{E}-11$ & 2.43 \\
20B & $1.00 \mathrm{E}-11$ & 2.67 \\
40B & $3.00 \mathrm{E}-12$ & 2.98 \\
60B & $5.00 \mathrm{E}-12$ & 3.01 \\
\hline
\end{tabular}

As a general trend, it can be noticed that at similar $\Delta K$ values, the higher the boron content, the lower the crack propagation rate, especially at low $\Delta K$ values. This behavior is also observed on the reduction for the parameter $\mathrm{C}$ in every single sample where the average boron content increases (see table 2). However, at high $\Delta K$ values the dependence on the $B$ content is less evident, a fact that can be explained by the increasing values of the slope $m$ in Paris' law. Similar trends have been reported in the literature [11, 32].

\subsection{Fractographic analysis of toughness}

Fracture of these bainitic steels shows a quasi-cleavage behavior. However some areas with dimple and void coalescence (indication of the existence of some ductility behavior) can be observed in Figure 8. That phenomenon can be seen in isolated areas of the micrographs, not as a generalized behavior. Results of the measurement of coalesced microvoids in each micrograph are shown in table 3 . It is notable that the percentage of coalesced microvoids in the analyzed micrographs increases in the bainitic steels with higher boron content.

Figure 9 shows the fracture surface produced by fracture toughness test of the bainitic steel $60 \mathrm{~B}$ at greater magnifications. Here, precipitates can be seen, and around them an area with cup-like depressions as a product of microvoid coalescence. In Figure 9b, another amplification, focused on those coalesced microvoids, shows coalesced nanovoids due to the presence of nearby second-phase particles, which results from separate precipitates, producing a considerable plastic strain during the tensile deformation [33].
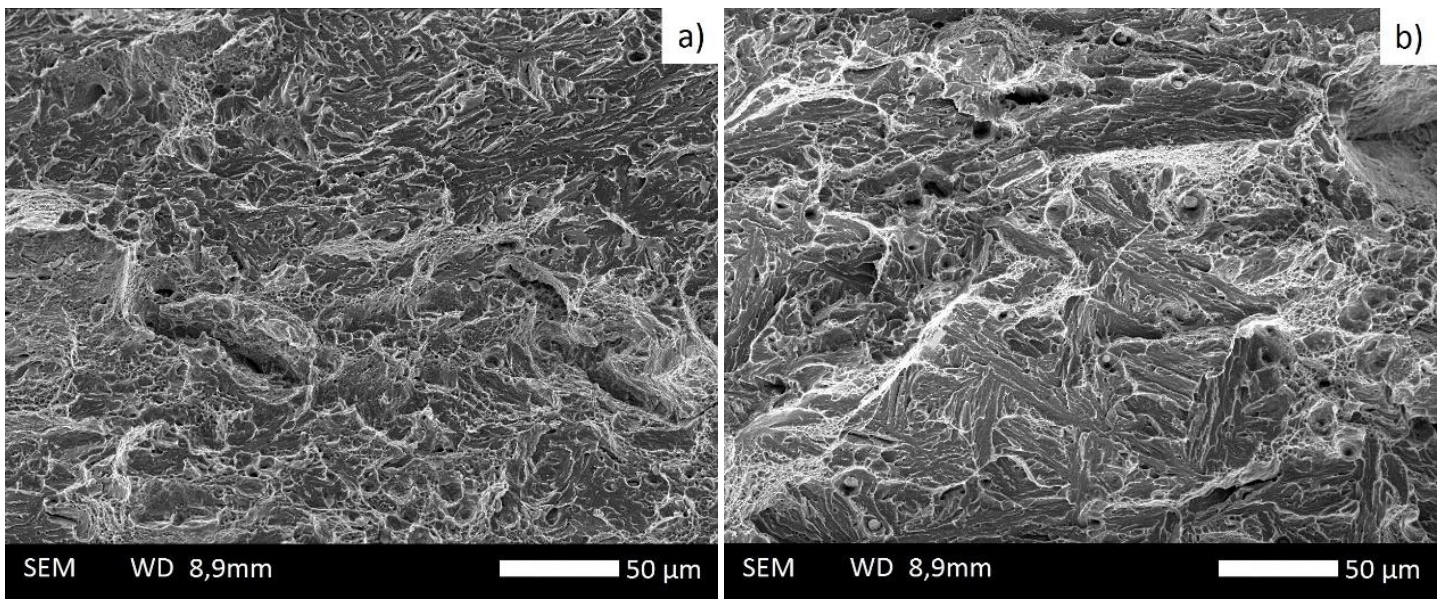

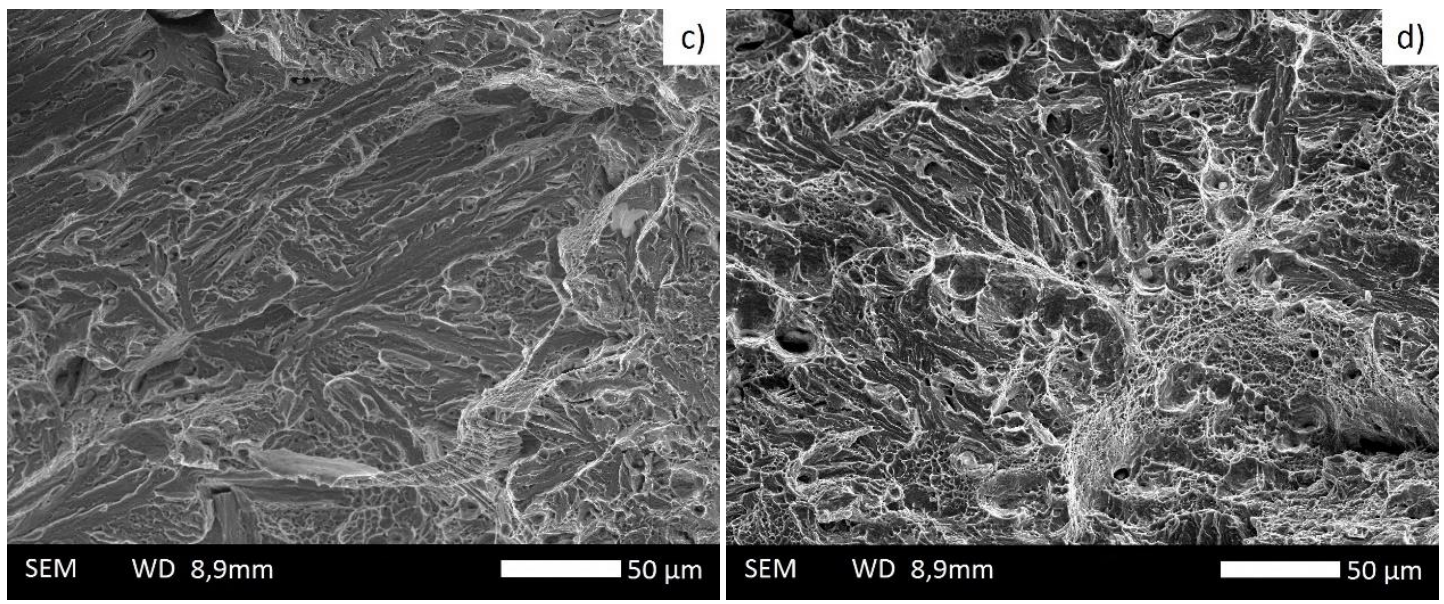

Figure 8. SEM of fracture areas generated by $J$ Integral test. a) Sample of bainitic steel $0 B$, b) Sample of bainitic steel 20B, c) Sample of bainitic steel with 40B and d) Sample of bainitic steel with $60 \mathrm{~B}$.

Table 3. Values of ductility of each specimen of bainitic steel.

\begin{tabular}{cc}
\hline Steel specimen & Ductility percentage \\
\hline $0 \mathrm{~B}$ & $36.15 \%$ \\
20B & $51.88 \%$ \\
40B & $58.82 \%$ \\
60B & $74.91 \%$ \\
\hline
\end{tabular}
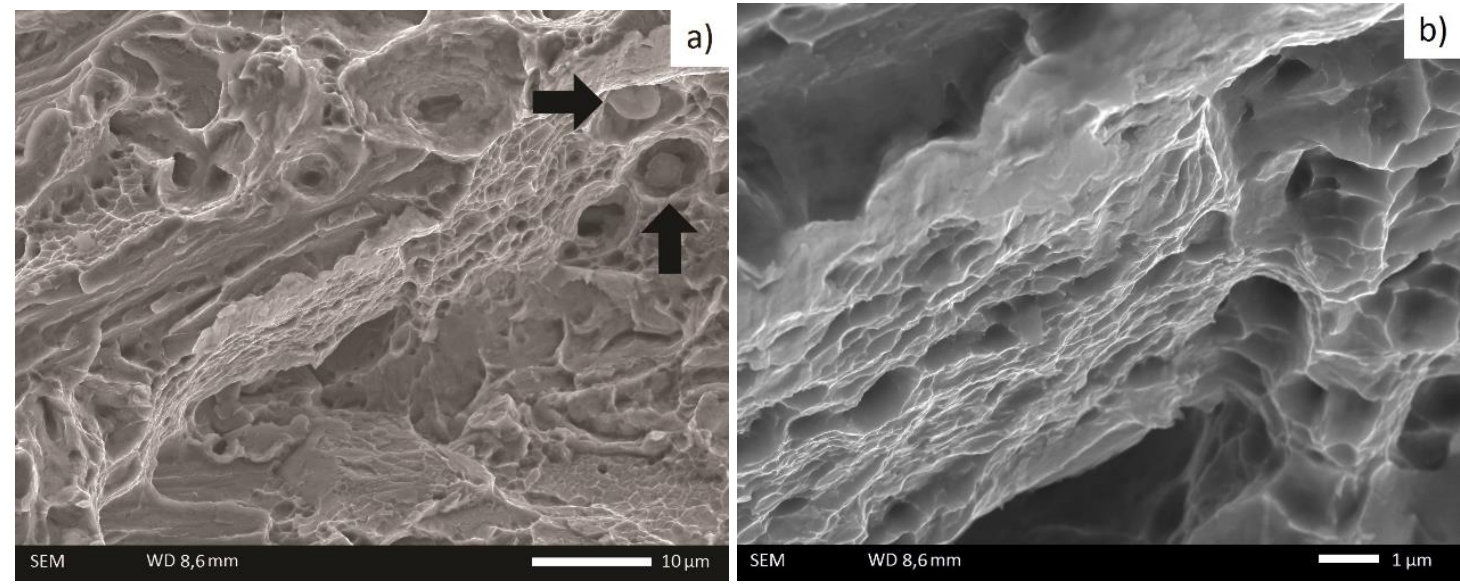

Figure 9. SEM, amplification of Figure $8 \mathrm{~d}$ ). a) Amplification that reveals presence of microvoids and precipitates (arrows). b) Amplification of Figure 9a that shows nanovoids as a product of ductility near a precipitate.

\subsection{Fractographic analysis of crack propagation}

Figure 10 shows an SEM micrograph of the fatigue crack in a normal direction along the longitudinal axis, generated in bainitic steel sample OB. In the longitudinal direction of the samples, secondary cracks can be observed, appearing beside the principal propagated crack, with an incomplete effect of the etch on the surface of the sample. Figure 10a shows that in areas closer to the crack propagated by fatigue, secondary cracks are seen. 
Figure $10 \mathrm{~b}$ is a magnification of Figure 10a, and it reveals small cracks between the bainite plates and the matrix of bainitic ferrite; these cracks can be considered to be energy absorption points, because at the top of the crack, energy must be dissipated in order to allow the crack growth process, according to Griffith's criterion. The principal propagated crack can be seen at the top of the micrograph.

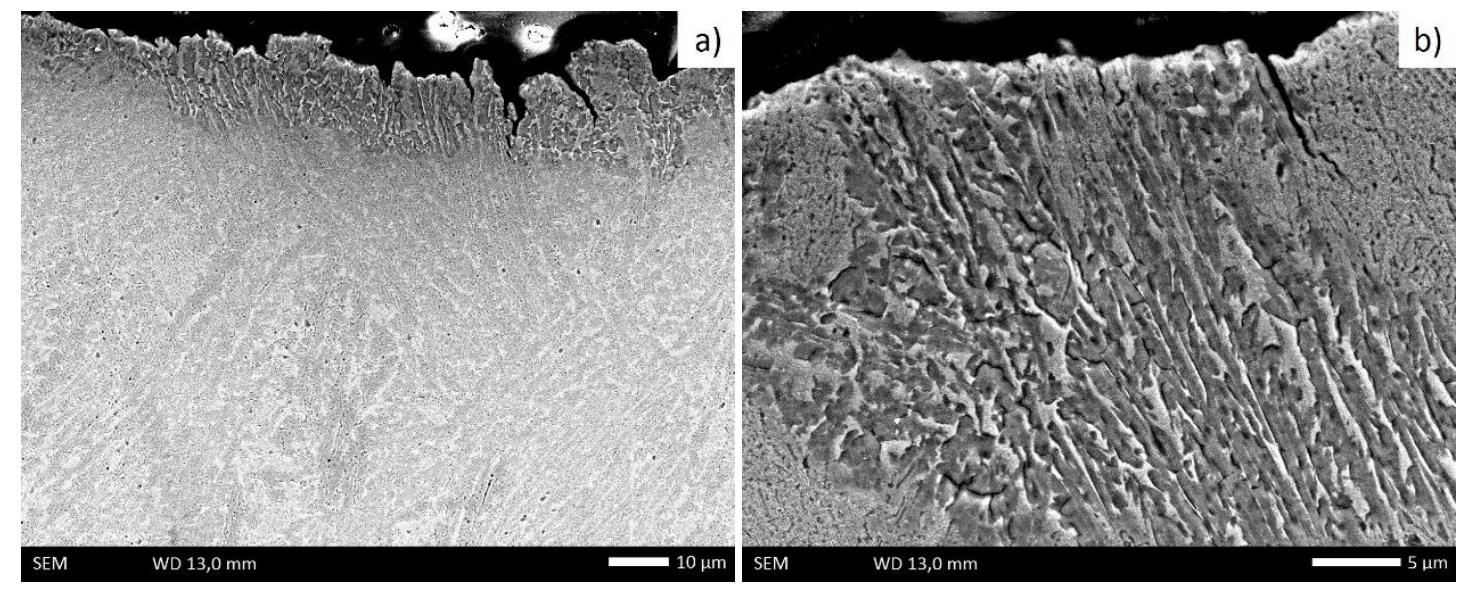

Figure 10. a) SEM micrograph of fatigue crack of a bainitic steel 0B, b) Amplification of the top of Figure 10a.

Micrographs of the top of the notch where the fatigue crack starts in 60B bainitic steel sample are shown in Figure 11. Figure 11a shows changes of growth planes through the crack growth. Those planes have a tendency to be orientated in a direction close to 45 degrees from longitudinal axis of the sample, in accordance with previous studies [28]. Likewise, in Figure $11 \mathrm{~b}$ it is notable that in a bainitic microstructure, the crack growth process is through bainite grains (transgranular) and not along grain boundaries. Generally, materials that present transgranular cracks exhibit a higher toughness than materials with cracks through the grain boundaries, due to the fact that the growth of the cracks is related to a high degree of plastic strain previous to the crack formation [34]. In Figure 11b, which corresponds to steel sample $60 \mathrm{~B}$, longitudinal cracks are not seen, as was the case in Figure 10b, showing a higher resistance to the propagation of cracks along the material (toughness) in bainitic steels with the addition of boron, corresponding to the analysis made in section 3.2.

Figure 12 shows SEM micrographs of cross-sectional areas of the crack growth surfaces of steels $\mathrm{OB}$ and $60 \mathrm{~B}$. Comparison of the transversal micrographs of Figure 12a and Figure 12c of steel samples $\mathrm{OB}$ and $60 \mathrm{~B}$, respectively shows how tearing decreases on the fracture surface of the sample with the addition of boron. The longitudinal fractures observed in Figure $12 \mathrm{~b}$ also tend to disappear in Figure 12c. 

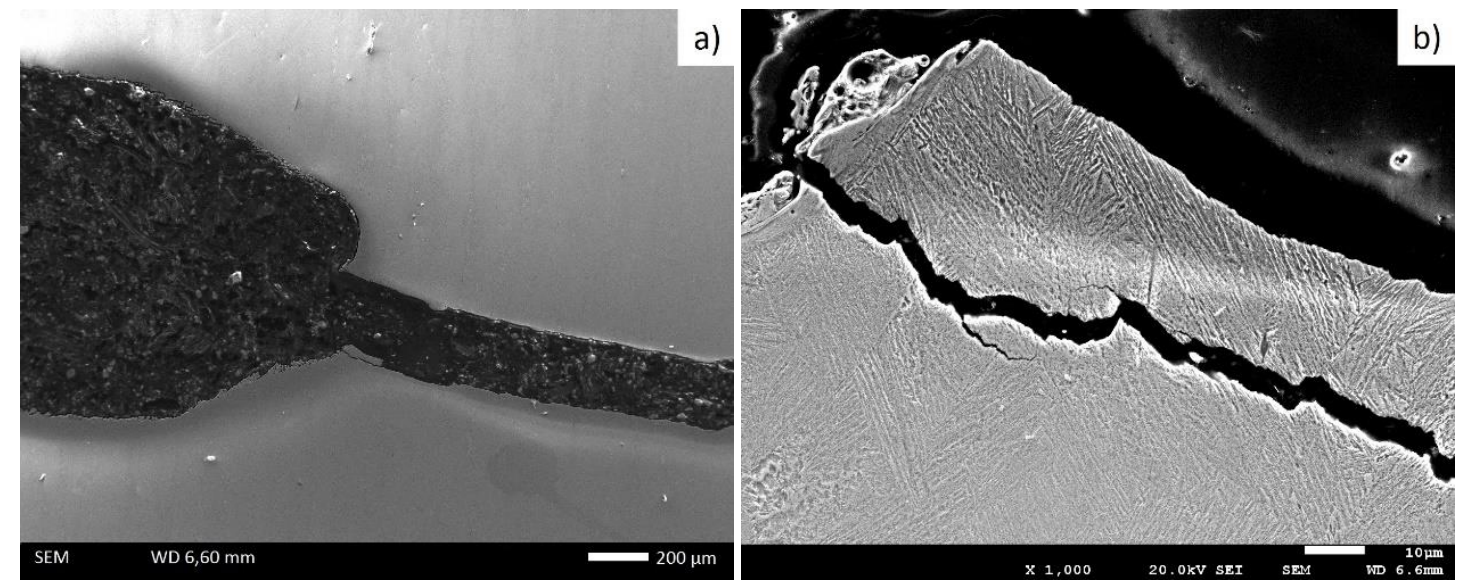

Figure 11. a) SEM micrograph of bainitic steel with $60 \mathrm{~B}$, at the top of the notch a fragment appears. b) Amplification of 11 a) which reveals a transgranular fracture.
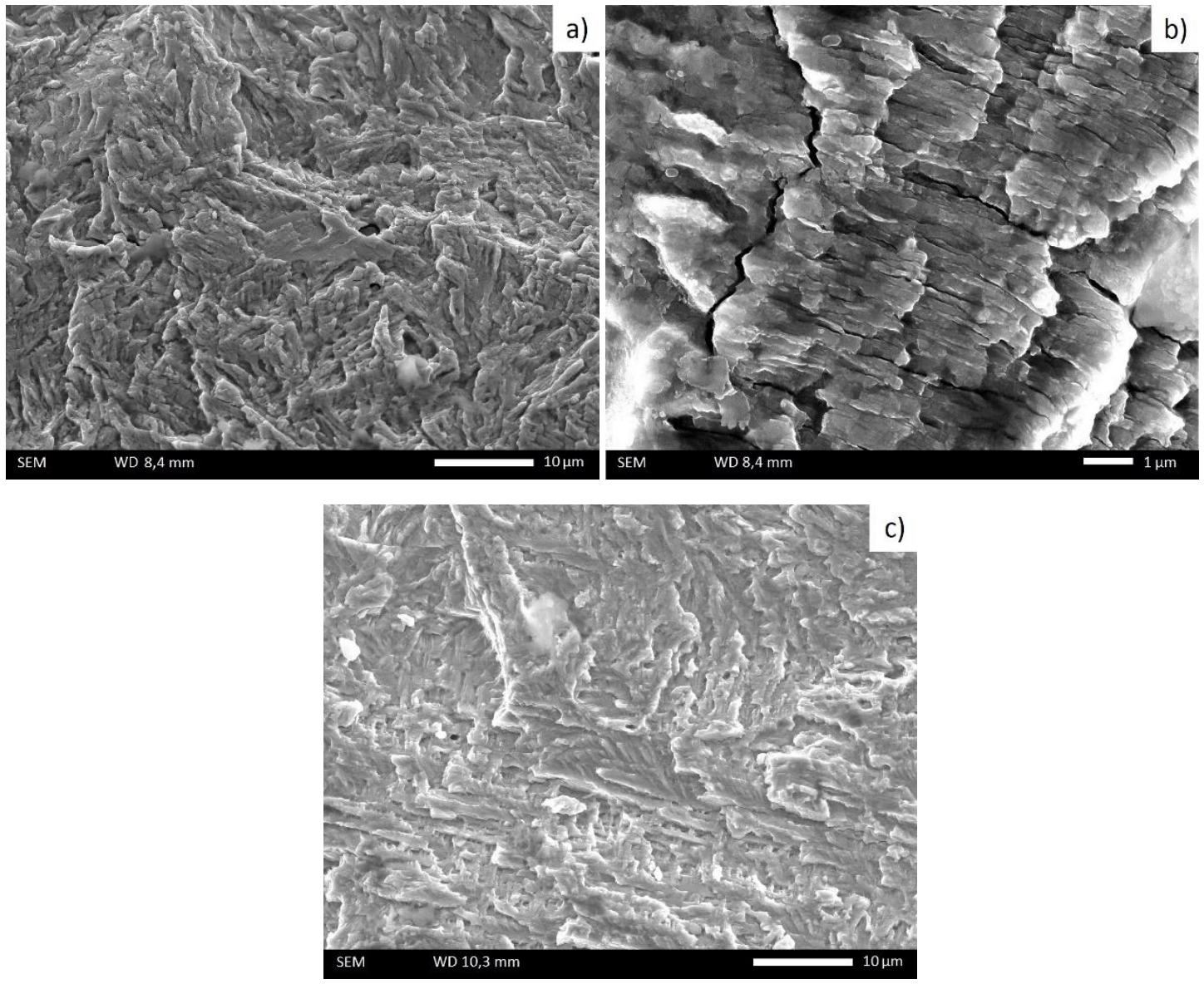

Figure 12 a). SEM micrograph of cross sectional areas of the crack growth surfaces of a sample of bainitic steel a) 0B, b) Amplification of Figure 12a which shows the presence of longitudinal cracks. c) Ductile tearing and ridge formation in bainitic steel $60 \mathrm{~B}$.

A cross-sectional area of crack growth in a sample of OB steel is shown in Figure 13. It reveals ductile tearing and ridge formation. These behaviors are associated with bainitic steels; ridges in the micrograph have some lines orientated in every crack plane. Figure 13a shows these lines in an amplified fracture plane. The presence of some cavities in the shape of plates, in a range from 1 to $1.5 \mu \mathrm{m}$, is noticeable. The thicknesses of the bainite plates in Figure 1a are within a range from $0.5 \mu \mathrm{m}$ to $1.6 \mu \mathrm{m}$; this range includes the range of cavity thicknesses of 
Figure 13a. Figure 13b shows an amplification of Figure 13a. A crack in the edge of a bulge with the appearance of a bainitic plate can be seen, demonstrating the fact that those cavities were generated by the separation of the bainitic plates from the bainitic ferrite and other components throughout every single pack.
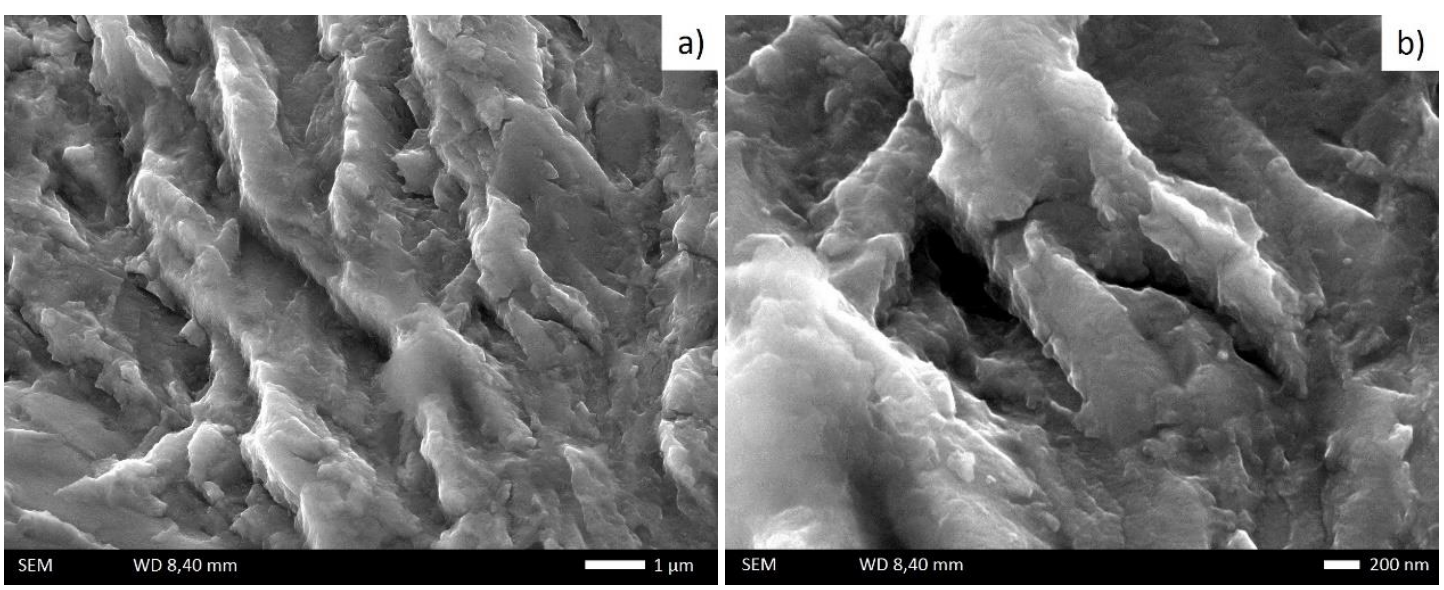

Figure 13 a). SEM micrograph of cross sectional area of crack propagation in bainitic steel. b) Amplification of Figure 13a.

\subsection{Possible interpretation of toughness enhancement}

In the present paper, bainitic steels with the addition of boron in which the amount of retained austenite before thermo-mechanical transformation is relatively small are presented; after that, it can be seen in Figures 3 and 5 that the amount of martensite and austenite tends to disappear as mean boron content increases in the steels samples. In agreement with preceding research $[31,35]$, the main effect of boron in steel is to accelerate the transformation of austenite to ausferrite, which is a microstructure that consists of carbide-free ferrite and highcarbon austenite during bainitic transformation by heat treatment, causing lower values of retained austenite in steels to which boron has been added. Furthermore, large blocks of retained austenite tend to mechanically transform to a small grain-size retained austenite at relative large strains. It is known that the microstructural feature responsible for crack nucleation is the boundaries between martensite bands and the bainite matrix [15], producing lower values of toughness in steels with a higher content of martensite; additionally, there is a small grain size of interlath martensite/austenite, which produces microstructural discontinuities that favor crack propagation in the bainitic steels studied in this paper.

Furthermore, after the thermo-mechanical transformation, it can be seen how in multiple bainite plates with the same crystallographic orientation, at the austenite grain boundary, only one bainitic lath, more robust than the others, tends to be created, with larger proportions than average throughout the bainitic packets. The austenite films that are between the laths tend to disappear through the bainitic packet, producing a homogenous plate. Altogether, these phenomena are called bainite coalescence. Figure 14 shows thin laths of bainite in different packets; where packets have a similar direction, wider coalesced laths appears, indicated by the arrows. According to another investigation [36], bainite laths in steel have a tendency to coalesce when the bainitic transformation is under conditions of stress; that is, because the number of crystallographic variables is reduced, that gives an orientation to the grains and sheaves of bainite, promoting the conditions for bainite coalescence. That directional tendency of the bainitic microstructure can be observed in bainitic steels of the 
current paper because of the applied stress due to strain in the thermo-mechanical bainitic transformation.

In this paper, all manufactured steels have the same fabrication conditions, having a tendency to form bainite plates at approximately 45 degrees from the rolling axis, which is the reason that it cannot be concluded that bainite coalescence has an effect on the enhancement of the toughness of bainitic steels obtained in Figure 6. Also, it is known that coarse plates are detrimental to toughness, which is the reason that the toughness values obtained for these steels are lower than the results reported by other researchers [15, 37].

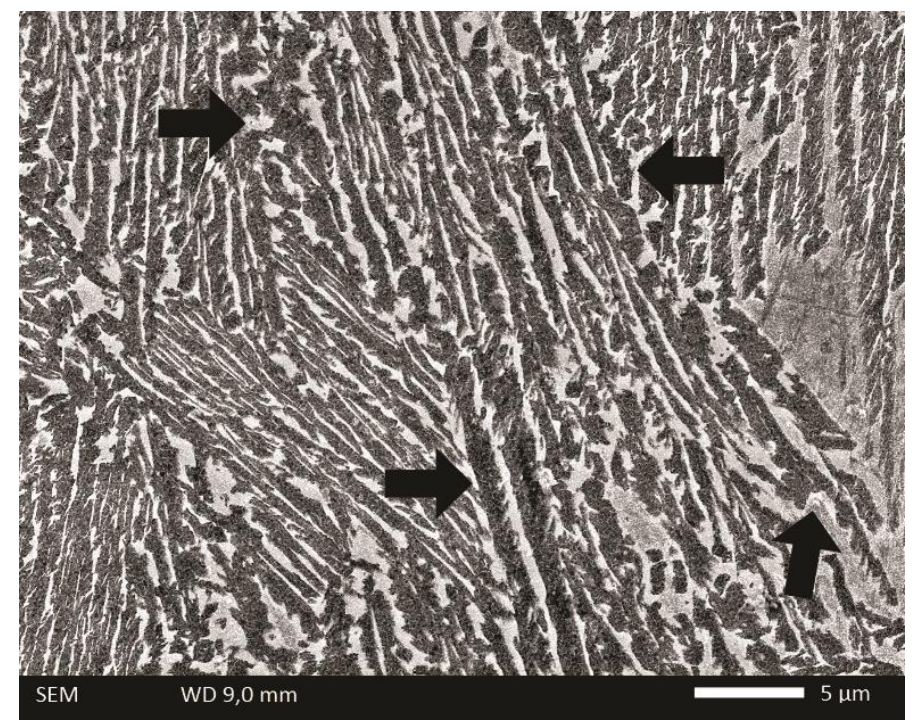

Figure 14. SEM micrograph that shows sections where oriented bainitic plates are coalesced and increase their thickness in a sample of bainitic steel 60B.

Results of published studies [15] show that void nucleation occurs through different phenomena, such as martensite cracking, separation of adjacent martensite regions, or decohesion at the ferrite/martensite interface, when the martensite phase is in relatively small grains. This phenomenon is reduced upon an increase of the martensite grain size, which is the reason that bainitic steels with a higher amount of boron, having a smaller presence of martensite in accordance with Figure 5, exhibit a significant enhancement of toughness. Furthermore, Figure 8 and Figure 9 reveal that there is a greater amount of nucleated microand nano-voids close to micro-size particles seen in the steels with a higher amount of boron. This particles e identified as titanium boride $B_{2} T i$, increases the plastic strain along the fracture surface, thus producing a higher value of fracture toughness in $60 \mathrm{~B}$ steels.

\section{Conclusions}

The addition of boron to hot-rolled bainitic steels promotes variations in the amount of martensite and retained austenite, followed by a change in fracture toughness. The experimental approach adopted here aimed at evaluating how the fracture toughness and the fatigue life of hot-rolled bainitic steels change with the addition of boron, and how crack propagation through the bainitic microstructure can explain that phenomenon. It was found that: 
- The grain size of hard constituents such as Martensite and M/A inside bainite sheaves decreases with the addition of boron, favoring conditions for the presence of microvoid coalescence on the fracture surface. This increases the energy absorbed by the material through the fracture, promoting greater values of toughness in steels with added boron.

- Furthermore, small additions of other chemical elements, such as titanium, which has a strong tendency to react with boron, produce small amounts of precipitates, which increases the micro-void coalescence and the fracture toughness of the bainitic steels.

- Bainitic steels $40 \mathrm{~B}$ and 60B exhibit a higher crack deceleration rate in the second stage of Paris' law, indicated by the lower slope in comparison with bainitic steels $O B$ and 20B. At the same time, secondary cracks through bainite packets tend to disappear in bainitic steels $40 \mathrm{~B}$ and $60 \mathrm{~B}$, which also indicates that resistance to fatigue crack propagation rises in bainitic steels as the addition of boron increases in the range from 0 to 60 parts per million of boron.

- The crack growth process is transgranular in hot-rolled bainitic steels. Crack propagation among bainite laths involves a continuous change in crack tip direction across bainitic packets. Crack direction changes in every single bainite packet, forcing the crack to traverse longer trajectories than in a non-directional material, producing crack branches in the longitudinal direction of the sample, indicating a higher energyconsuming process. This causes a higher degree of toughness and a longer fatigue life.

- In the crack propagation process, through the crack path, it can be seen that nanocracks, which appear between the laths and the bainitic matrix, have a strong tendency to separate themselves, revealing the behavior of the crack growth in a bainitic microstructure.

\section{Acknowledgements}

The authors acknowledge with appreciation the financial support received from the Spanish Ministry of Economy and Competitiveness through the project MAT2011-29039-C02-01 and from the department of Vice-rector of Research of the National University of Colombia. Thanks for the technical support from the foundry laboratory and Mr Sierra from National University of Colombia.

\section{References}

[1] Irvine KJ, Pickering FB. The metallography of low-carbon bainitic steels. J. Iron Steel Inst 1958; 188: 101-112.

[2] Bhadeshia HKDH. Bainite in Steels: transformations, micostructure and poperties. 2nd ed. London: The Inst of Mater; 2001.

[3] Caballero FG, Allain S, Cornide J, Puerta Velásquez JD, Garcia-Mateo C, Miller MK. Design of cold rolled and continuous annealed carbide-free bainitic steels for automotive application. Mater Design 2013; 49: 667-680. 
[4] Fielding L. The bainite controversy. Eng Mater Sci Technol 2013; 29: 383-399.

[5] Zhang FC, Yang ZN, Kang J. Research progress of bainitic steel used for railway crossing. J Yanshan Univ 2013; 37: 1-7.

[6] Sajjadi SA, Zebarjad SM. Isothermal transformation of austenite to bainite in high carbon steels. J Mater Process Technol 2007; 189: 107-113.

[7] Zhu K, Oberbillig C, Musik C, Loison D, Lung T. Effect of $B$ and $B+N b$ on the bainitic transformation in low carbon steels. Mater Sci Eng, A 2011; 528: 4222-4231.

[8] Sung HK, Lee DH, Shin SY, Lee S, Yoo JY, Hwang B. Effect of finish cooling temperature on microstructure and mechanical properties of high-strength bainitic steels containing Cr, Mo, and B. Mater Sci Eng, A 2015; 624: 14-22.

[9] Chun F, Hong-sheng F, Yan-kang Z, Bing-zhe B. Mn-series low-carbon air-cooled bainitic steel containing niobium of 0.02\%. J Iron Steel Res Int. 2010, 17(4): 53-58.

[10] Aglan HA, Fateh M. Fracture and fatigue crack growth analysis of rail steels. J Mech Mater Struct 2007; Vol 2 No. 2: 335-346.

[11] Aglan HA, Fateh M. Microstructure-fatigue crack propagation kinetics relationships of rail steels. J Civ Eng 2010; 4(9): 34.

[12] Aglan HA, Liu ZY, Hassan MF, Fateh M. Mechanical and fracture behavior of bainitic rail steel. j mater process tech 2004; 151: 268-274.

[13] Lambers, H. G., Gorny, B., Tschumak, S., Maier, H. J., \& Canadinc, D. (2010). Crack growth behavior of low-alloy bainitic 51CrV4 steel. Procedia Eng; 2(1): 1373-1382.

[14] Lan HF, Du LX, Misra RDK. Effect of microstructural constituents on strengthtoughness combination in a low carbon bainitic steel. Mater Sci Eng, A 2014; 611: 194200.

[15] Caballero FG, Chao J, Cornide J, García-Mateo C, Santofimia MJ, Capdevila C. Toughness deterioration in advanced high strength bainitic steels. Mater Sci Eng, A 2009; 525: 87-95.

[16] Zhu ML, Xuan FZ, Wang GZ. Effect of microstructure on fatigue crack propagation behavior in a steam turbine rotor steel. Mater Sci Eng, A 2009; 515: 85-92.

[17] Caballero FG, Santofimia MJ, Capdevila C, García-Mateo C \& García de Andrés C. Design of advanced bainitic steels by optimisation of TTT diagrams and TO curves. ISIJ Int 2006; 46(10), 1479-1488.

[18] Yang JR, Huang CY, Wang SC. The development of ultra-low-carbon bainitic steels. Mater Design 1992; 13(6): 335-338.

[19] Lan L, Qiu C, Zhou P, Zhao D, Li C, Gao X, Du L. Effect of boron addition on the microstructures and mechanical properties of thermomechanically processed and tempered low carbon bainitic steels. Acta Metall. Sin.(Engl. Lett.) 2011; 24 (6): 473486. 
[20] Wang SC, Kao PW. The effect of alloying elements on the structure and mechanical properties of ultra low carbon bainitic steels. J Mater Sci 1993; 28(19): 5169-5175.

[21] Tamehiro H, Murata M, Habu R, Nagumo M. Optimum microalloying of niobium and boron in HSLA steel for thermomechanical processing. T Iron Steel I JPN 1987; 27(2): 120-129.

[22] Melloy GF, Slimmon PR, Podgursky P. Segregation and the strength of grain boundaries. Met Transitions 1973; 4: 2279-2289.

[23] Su X, Clayton P. Surface-initiated rolling contact fatigue of pearlitic and low carbon bainitic steels. Wear 1996, 197: 137-144.

[24] Clayton P, Jin N. Unlubricated Sliding and Rolling/Sliding Wear Behavior of Continuously Cooled, low/medium carbon bainitic steels. Wear 1996; 200(1): 74-82.

[25] Yokoyama H, Mitao S, Yamamoto S, Kataoka Y, Sugiyama, T. High strength bainitic steel rails for heavy haul railways with superior damage resistance. NKK Tech Rep-Japanese Edition- 2000; 17-23.

[26] Aglan HA, Fateh M. Fatigue damage tolerance of bainitic and pearlitic rail steels. Int J Damage Mech 2006; 15(4): 393-410.

[27] ASTM Standard E1820-01: Standard Test Method for Measurement of Fracture Toughness. ASTM 2001.

[28] Pak J, Woo Suh D, Bhadeshia HKDH. Promoting the coalescence of bainite platelets. Scripta Mater 2012; 66: 951-953.

[29] Rancel L, Gómez M, Medina SF, \& Gutierrez I. Measurement of bainite packet size and its influence on cleavage fracture in a medium carbon bainitic steel. Mater Sci Eng, A 2011; 530: 21-27.

[30] Schick HL. Thermodynamics of certain refractory compounds. Volume II. Thermodynamic Tables, Bibliography, and Property File: Sections VII, VIII, IX. Air Force Materials Lab Wright-Patterson AFB OH 1966.

[31] Zhou Q, Qian L, Tan J, Meng J, Zhang F. Inconsistent effects of mechanical stability of retained austenite on ductility and toughness of transformation-induced plasticity steels. Mater Sci Eng, A 2013; 578: 370-376.

[32] Deng X, Piotrowski GB, Chawla N, Narasimhan KS, Marucci M. Fatigue Crack Growth of Prealloy Fe-0.85 Mo-2Mi-0.6 C Steels With a Homogeneous Microstructure. Adv Powder Metall Part Mater 2005; 3 (10): 111-124.

[33] Firrao D, Begley JA, De Benedetti B, Roberti R, Silva G. Fracture initiation and propagation at the root of the notch in as-quenched AISI 4340 steel Charpy type bars with varying notch root radii. Scripta Metall Mater 1980; 14(5): 519-524.

[34] Pardoen T, Dumont D, Deschamps A, Brechet Y. Grain boundary versus transgranular ductile failure. J Mech Phys Solids 2003; 51 (4): 637-665. 
[35] Bedolla-Jacuinde A, Guerra FV, Rainforth M, Mejía I, Maldonado C. Sliding wear behavior of austempered ductile iron microalloyed with boron. Wear 2015; 330: 23-31.

[36] Pak J, Suh DW, Bhadeshia HKDH. Promoting the coalescence of bainite platelets. Scripta Mater 2012; 66(11): 951-953.

[37] Rancel L, Gómez M, Cabrera Marrero JM, Medina SF. Influence of chemical composition and tempering treatment on toughness of bainitic $38 \mathrm{MnV7}$ steel. Steel res Int 2012; 1171-1174. 